\title{
Motivação de gestantes para o aleitamento materno ${ }^{1}$
}

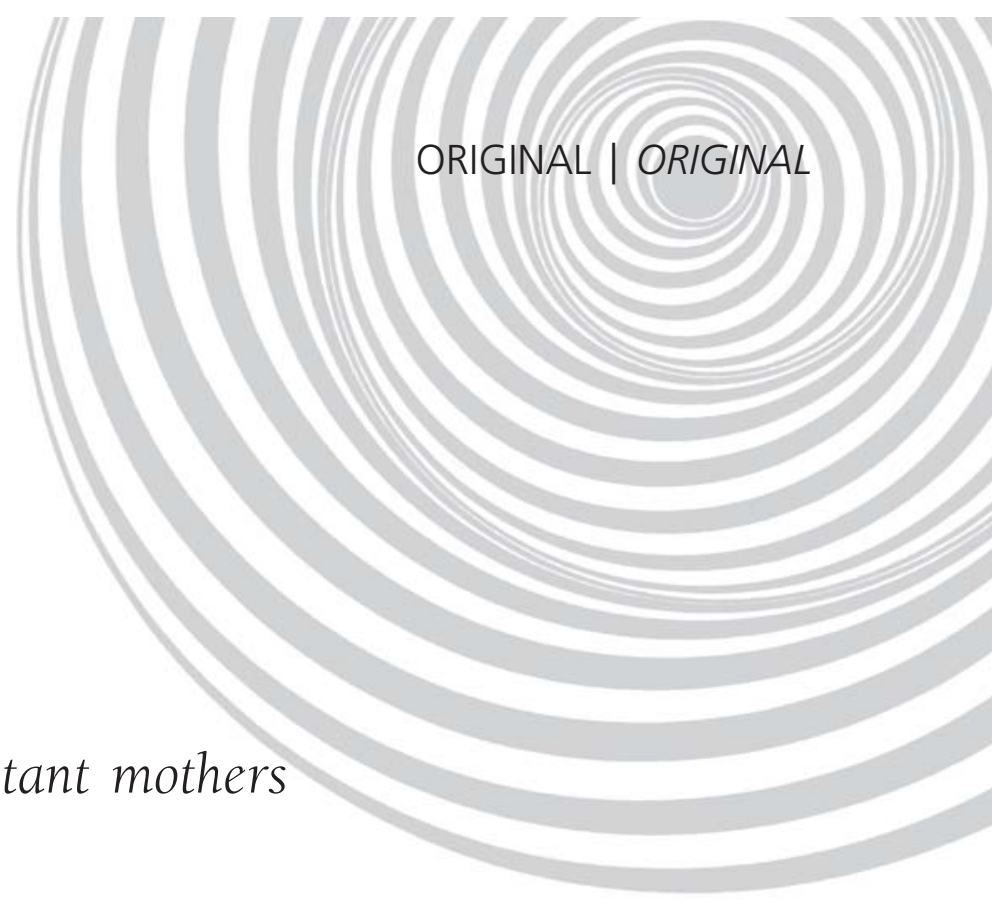

Sueli Aparecida Moreira TAKUSHI ${ }^{2}$

Ana Cristina d'Andretta TANAKA²

Paulo Rogério GALLO²

Maria Aparecida Miranda de Paula $\mathrm{MACHADO}^{3}$

\section{RE S U M O}

\section{Objetivo}

Conhecer os motivos de gestantes para o aleitamento materno.

\section{Métodos}

É um estudo qualitativo realizado com 164 gestantes assistidas no pré-natal em dois Centros de Saúde na região central da cidade de São Paulo. Os dados foram coletados por meio de entrevistas semi-estruturadas sobre motivação para amamentar. As narrativas foram organizadas em planilha eletrônica em busca de categorias.

\section{Resultados}

As principais categorias identificadas estavam relacionadas à saúde da criança, da mulher e aos benefícios da prática de amamentar e do leite materno. A maioria das mulheres $(98,8 \%)$ foi favorável à amamentação. Benefícios à saúde da criança foi o motivo mais freqüente $(73,8 \%)$.

\section{Conclusão}

A motivação ao aleitamento materno foi centrada nos benefícios à saúde da criança. A amamentação é valorizada independentemente da vontade materna.

Termos de indexação: Aleitamento materno. Comportamento materno. Cuidado pré-natal.

\section{A B S T R A C T}

\section{Objective}

The present study sought to discover the reasons for expectant mothers to breastfeed.

1 Apoio financeiro: Conselho Nacional de Desenvolvimento Científico e Tecnológico (Processo n.133519/00-7).

2 Universidade de São Paulo, Faculdade de Saúde Pública, Departamento de Saúde Materno-Infantil. Av. Dr. Arnaldo 715, Sala 218, 01246-904, São Paulo, SP, Brasil. Correspondência para/Correspondence to: S.A.M. Takushi. E-mail: <suelimoreira@yahoo.com.br>.

${ }^{3}$ Universidade de São Paulo, Faculdade de Odontologia de Bauru. Bauru, SP, Brasil. 
492 | S.A.M. TAKUSHI et al.

\section{Methods}

This was a qualitative study involving 164 expectant mothers attending prenatal care in two health centers of the city of São Paulo. Semi-structured interviews were done to collect data on the reasons to breastfeed. The information was organized in a spreadsheet to search for categories.

\section{Results}

The main identified categories regarded the child's and woman's health and the benefits of breastfeeding and breast milk. The majority of the women (98.8\%) regarded breastfeeding favorably. Benefit to the child's health was the reason mentioned most often (73.8\%).

\section{Conclusion}

Motivation to breastfeed was based on benefits to the child's health. Breastfeeding is valued regardless of the mother's will.

Indexing terms: Breast feeding. Maternal behavior. Prenatal care.

\section{N T R O D U ÇÃ O}

O aleitamento materno é uma etapa do processo reprodutivo feminino cuja prática resulta em benefícios para a saúde da mulher e da criança envolvidas no processo da amamentação, com repercussões positivas para a sociedade. Ao optar pela prática, a mãe além de prover o alimento ao filho, mantém proximidade corporal repleta de sentidos para a relação mãe e filho.

No Brasil, desde o Império, a amamentação era enfatizada pela literatura da época por ser mais saudável e como medicamento para qualquer doença da criança ${ }^{1}$. Ao final do século XIX, acreditava-se ${ }^{2}$ que a mortalidade infantil muito elevada resultasse das condições sociais desfavoráveis e do afastamento das leis naturais no modo da alimentação infantil. Portanto, inspecionar o regime de lactação e regulamentá-lo segundo os princípios da higiene infantil passou a constar, desde então, do estatuto de proteção e assistência à infância².

Diante disso, o aleitamento materno, processo aparentemente fisiológico inerente à espécie, pode ser condicionado aos aspectos socioculturais $^{3}$ e aos fatos históricos. A prática de amamentar não é instintiva e, portanto, requer ser aprendida pela mulher e protegida pela sociedade ${ }^{3}$. Culturalmente, o sucesso da amamentação qualifica o desempenho materno como uma das representações sociais mais importantes na vida da mulher. Ao sucesso desta prática se vincula o conceito de mãe suficientemente boa ${ }^{4}$, apregoado pela literatura médica clássica de Winicott ${ }^{4}$, que legitimou, nos anos 60, a difusão desta crença em relação às mulheres.

A motivação é uma das estratégias conferidas no processo de decisão da mulher em direção à prática do aleitamento materno. No percurso entre o desejo de amamentar e a concretização da prática, a motivação é o que permeia este processo de decisão materna, de modo favorável ou contrário. É condicionada pela história de vida da mulher e pela sua experiência passada, incluindo o conhecimento adquirido desde a infância, por observação de alguém da família amamentando 3 , pelo que foi aprendido e facilitado no contexto das oportunidades socioculturais e, por último, pelo conhecimento adquirido durante a assistência pré-natal e pediátrica ${ }^{5,6}$.

Fatores de ordem social atuam no contexto familiar influenciando diretamente a prática. $\mathrm{O}$ trabalho feminino, por exemplo, pode implicar na duração da amamentação de forma exclusiva 5 . Condições maternas relacionadas à anatomia das mamas podem dificultar o estabelecimento da amamentação, consistindo em impedimento físico que desestimula a intenção de amamentar. Por outro lado, o sucesso do aleitamento materno também depende da habilidade de sucção da criança, ato reflexo importante para a estabilidade do lactente à mama7.

Do ponto de vista bioquímico, o leite materno tem sido amplamente enaltecido tanto pela capacidade de suprir os requerimentos 
nutricionais e hídricos da criança até o sexto mês de vida, quanto pelo complexo imunológico que protege a saúde gastrintestinal da mesma ${ }^{3,8}$. Os benefícios da prática e da adequada composição nutricional vêm obtendo êxito na redução da mortalidade infantil, principalmente, em condições insatisfatórias de saneamento básico. No Brasil, a superioridade nutricional do leite humano traduzse no principal argumento de incentivo ao aleitamento materno exclusivo para reverter a prática freqüente de oferta de alimentos ao recémnascido desde o início da amamentação ${ }^{5}$.

A amamentação também resulta em benefícios para a saúde reprodutiva da mulher, pois sua prática freqüente com mamadas duradouras contribui para preservar a saúde materna ao ampliar o espaçamento entre gestações e partos $^{3,8}$. Vantagens para a relação mãe e filho podem ser reportadas tendo em vista que, para amamentar, a mãe adquire o costume de oferecer aconchego à criança, promovendo o vínculo afetivo desejável na relação mãe e filho. Outros ganhos com a amamentação incluem a praticidade e a isenção de despesas com substitutos do leite materno ${ }^{3}$.

O primeiro passo do processo de tomada de decisão pela prática do aleitamento materno é identificar o desejo materno em amamentar. Marques et al. ${ }^{9}$ encontraram que o desejo pela amamentação expresso durante a gestação resultou, na maioria das vezes, no início da efetivação da prática. É, segundo Silva ${ }^{10}$, durante a gestação que as mulheres decidem-se em relação ao aleitamento materno. A gestação permite, em tempo hábil, repensar a decisão. Sandre-Pereira et al. ${ }^{11}$, acrescentaram que todas as mães de seu estudo haviam desejado amamentar desde a gestação.

Ao considerar a assistência pré-natal como uma oportunidade ímpar para dialogar com mulheres sobre suas reais possibilidades e desejos para amamentar, realizou-se este estudo com o objetivo de apreender a motivação de gestantes no processo de decisão pelo aleitamento materno.

\section{MÉ T O D O S}

Realizou-se estudo exploratório de natureza qualitativa envolvendo a demanda de 164 gestantes usuárias da assistência pré-natal do Centro de Saúde Escola Barra Funda e do Centro de Saúde Geraldo de Paula Souza, que se encontravam em salas de espera para consulta médica do serviço de pré-natal. Os Centros de Saúde localizam-se na região central da cidade de São Paulo, em região distrital de baixa fecundidade.

A escolha das participantes foi determinada pela demanda de mulheres atendidas no período de março a agosto de 2002 nos dois Centros de Saúde. As mulheres residiam ou trabalhavam nas proximidades dos Centros de Saúde, em serviços domésticos e em oficinas de costura da região. As mulheres recebiam assistência de equipe de saúde composta de médico obstetra, enfermeira e psicóloga. Nos consultórios existiam cartazes sobre aleitamento materno ressaltando a duração ideal de seis meses.

Os dados foram obtidos por meio de entrevista semi-estruturada realizada pela pesquisadora com cada usuária, em sala de espera, durante o intervalo entre as consultas médicas. Com auxílio de roteiro, a questão da intenção de amamentar foi abordada por meio da seguinte pergunta: $A$ senhora pretende amamentar? Enquanto que a motivação foi apreendida com a pergunta: Por que a senhora pretende amamentar?

As narrativas foram apreendidas a partir de uma abordagem qualitativa com o senso prático, proposto por Bauer \& Gaskell ${ }^{12}$, de que os relatos de determinado grupo, como o de gestantes, expressam a verdade de um ponto de vista, de uma situação específica no tempo e no espaço. Foram, portanto, consideradas como representações ou interpretações particulares destas mulheres.

Para a análise, as narrativas foram organizadas em planilha eletrônica que permitiu categorizar e agrupar os motivos nas seguintes classes: atributos do leite materno; benefícios para a saúde da criança; vantagens para a saúde da mulher; 
494 | S.A.M. TAKUSHI et al.

responsabilização da criança; prazer versus dever materno em amamentar; experiência prévia com amamentação e trabalho materno.

Este estudo foi realizado de acordo com as Normas e Diretrizes Éticas da Resolução CNS 196/96 do Ministério da Saúde, e aprovado pelo Comitê de Ética em Pesquisa da Faculdade de Saúde Pública em 12 de setembro de 2001 (Of.COEP/201/01).

\section{RESULTADOSE DISCUSSÃO}

As participantes eram mulheres jovens, com nível médio de escolaridade, sendo que mais da metade delas aguardavam pelo nascimento do primeiro filho. A maioria delas $(98,2 \%)$ demonstrou intenção favorável pela amamentação. Do restante, duas delas (1,2\%) admitiram não pretender amamentar, e outras duas (1,2\%) não tinham decidido ainda.

A decisão favorável, evidenciada pela maioria, em relação ao aleitamento materno reforça a informação de Silva ${ }^{10}$, de que a decisão sobre o aleitamento materno pode ocorrer ainda durante a gestação. Sandre-Pereira et al. ${ }^{11}$, ao abordarem puérperas sobre conhecimento de amamentação também notaram que todas elas haviam desejado, desde a gestação, praticar o aleitamento materno. Por outro lado, Marques ${ }^{9}$ notou que o desejo de amamentar e ou de ofertar outro leite em determinada idade, expresso durante a gestação, na maioria das vezes, se confirmou em realidade, com o que reforça a importância da assistência pré-natal em contribuir para que a mulher decida-se com autonomia. A estratégia de repetição às mulheres sobre o tempo que deve durar o aleitamento materno exclusivo não tem sido suficiente para conduzi-las a uma prática de alimentação complementar adequada ${ }^{11}$.

Benefícios para a saúde da criança foi o argumento freqüente apresentado por $73,8 \%$ de gestantes com intenção favorável para a amamentação. Na Tabela 1 encontram-se exemplos de frases a partir das quais as mulheres destacaram a saúde da criança como principal motivo da opção pelo aleitamento materno.

Nakano \& Mamede ${ }^{13}$ também observaram o comportamento materno de justificar a amamentação sob a ótica da criança e concluíram que os discursos técnicos e acadêmicos que embasam os Programas de Incentivo ao Aleitamento Materno estão dirigidos ao atendimento das necessidades da criança, não contemplando a mulher e suas especificidades.

No estudo realizado por Sandre-Pereira et al. ${ }^{11}$, a expressão do desejo materno de amamentar sempre apontava para a criança e acompanhava justificativas tais como é importante para o bebê ou é melhor para o bebê. Isso demonstra, segundo o estudo ${ }^{11}$, que o foco da amamentação está centrado na criança - sua saúde, suas necessidades. A mulher - sua saúde, seu prazer, seus direitos - fica em segundo plano.

Assim, a concentração de motivos para o aleitamento materno sob a ótica da saúde da criança reflete a maneira como tem sido motivada a amamentação, nos vários ambientes pelos quais as mulheres passaram, incluindo o espaço da assistência pré-natal, resultando em uma aprendizagem, predominantemente, motivada pela perspectiva de saúde da criança.

Ao avaliar o conhecimento de mães sobre aleitamento materno, Percegoni et al. ${ }^{14}$ notaram que $80 \%$ das mulheres atribuíram ter aprendido, durante a assistência pré-natal, que o leite materno é o melhor alimento para o crescimento e desenvolvimento. Enquanto no presente estudo, os motivos expressos referentes à composição nutricional do leite da mãe foi identificado em apenas 6,1\% de frases (Tabela 1), que evidenciavam que: o leite tem tudo, todo tipo de vitamina, cálcio e água. Contudo, parecia existir entre elas uma tendência a enaltecer o leite para além daquele de proveniência humana, como alimento perfeito para a nutrição infantil.

Sobre a presença de substâncias imunes no leite humano, o estudo de Minas Gerais ${ }^{14}$ verificou que $40,6 \%$ das mulheres mencionaram 
Tabela 1. Motivos atribuídos pelas gestantes para o aleitamento materno em centros de saúde. São Paulo (SP), 2002.

\begin{tabular}{|c|c|c|}
\hline Motivos & $\mathrm{n}$ & $\%$ \\
\hline $\begin{array}{l}\text { 1. Saúde da criança } \\
\text { "... Acho que é importante para a criança!" } \\
\text { "... Acho que é muito importante para o recém nascido ..." } \\
\text { "... É bom para a criança! Tem muitas vantagens para a criança ..." } \\
\text { "... Porque faz bem para o bebê! E eu quero o melhor para o meu filho!..." } \\
\text { "... Para a saúde do meu filho ficar forte!" } \\
\text { "... Porque é bom! Eu já estou tendo leite! A criança fica forte! ..." } \\
\text { "Porque eu sei que faz bem para o bebê! Só se eu não puder mesmo!" } \\
\text { "... Acho que a amamentação faz parte do futuro da criança, da saúde dela ..." } \\
\text { "... É bom para a criança, para o desenvolvimento e para a saúde da criança ..." }\end{array}$ & 121 & 73,8 \\
\hline $\begin{array}{l}\text { 3. Fatores de proteção do leite materno } \\
\text { "Acho que é bom, evita doenças e diarréia ..." } \\
\text { "Porque é importante até os seis meses. Evita doença ..." }\end{array}$ & 11 & 6,7 \\
\hline $\begin{array}{l}\text { 4. Benefícios para a saúde da mãe } \\
\text { "... Porque faz bem para o nenê, para os dois e emagrece ..." } \\
\text { "... Vou amamentar porque faz bem para o bebê, não para mim, mas para ele ..." }\end{array}$ & 6 & 3,7 \\
\hline $\begin{array}{l}\text { 5. Praticidade } \\
\text { "... É mais fácil do que ficar dando mamadeira daqui ... dali ..." } \\
\text { "... Porque faz bem e acho cômodo! ..." }\end{array}$ & 2 & 1,2 \\
\hline $\begin{array}{l}\text { 9. Dever ou obrigação } \\
\text { "... Porque tem que amamentar a criança quando nasce! ..." }\end{array}$ & 4 & 2,4 \\
\hline $\begin{array}{l}\text { 10. Prazer e beleza } \\
\text { "... Porque acho bonito! ..." } \\
\text { "... Porque acho gostoso! ..." }\end{array}$ & 4 & 2,4 \\
\hline $\begin{array}{l}\text { 11. Trabalho materno } \\
\text { "... Não quero que ele sofra quando eu voltar ao trabalho. Preciso trabalhar!" }\end{array}$ & 1 & 0,6 \\
\hline 12. Não haviam decidido ou não sabiam & 2 & 1,2 \\
\hline Total & 164 & 100,0 \\
\hline
\end{tabular}

a proteção do leite materno contra doenças, enquanto no presente estudo somente $6,7 \%$ de gestantes pretendiam querer amamentar porque, segundo elas, "o leite materno: ...evita doenças e diarréia".

A amamentação exclusiva confere a proteção pela composição do leite humano e por evitar a exposição da criança a outro padrão alimentar em idade inoportuna. Porém, no pre- sente estudo a falta de conhecimento sobre a superioridade da composição do leite humano ficou evidente com a pouca freqüência de motivos destacando o valor nutricional do leite da mãe, e pelo pouco número de mulheres reportando a proteção contra doenças obtida pela amamentação. Estes resultados coincidiram com o estudo de Giugliani et al. ${ }^{8}$, que documentou desconhecimento materno generalizado dos vários 
aspectos da amamentação sobretudo da composição do leite materno.

Benefícios da amamentação relacionados à saúde materna foram identificados nos relatos de apenas 3,7\% de mulheres (Tabela 1). A vantagem de emagrecer foi identificada na seguinte fala: porque faz bem para o nenê, para os dois e emagrece. Apesar de importante a preocupação materna com o controle de peso pós-parto, a perda de peso materno pela prática de amamentar ainda não está totalmente esclarecida, pelo menos não foi encontrada por Stabe ${ }^{15}$ associação estatisticamente significante entre retenção de peso pós-gestacional e duração ou tipo de aleitamento materno. O peso pós-gestacional se mostrara associado à dieta adotada na gestação ${ }^{15}$.

A motivação centrada no emagrecimento reforça a importância de agregar hábitos alimentares saudáveis às mulheres que pretendem engravidar ou logo no início da gravidez, explicando que a dieta indicada às gestantes nem sempre se aplica às crianças pequenas. Segundo Takushi $^{5}$, as mulheres apreendem a orientação nutricional no pré-natal, sem distinguir requerimentos nutricionais de adultos e crianças.

Em estudo realizado por Moreira \& Nakano ${ }^{16}$, envolvendo mulheres sob a perspectiva dos direitos reprodutivos, observou-se que a aprendizagem sobre amamentação, quando relacionada à saúde materna, ocorreu com o objetivo de assegurar boas condições ao aleitamento materno e não no sentido de conscientizar a mulher para o fato de que acontece no seu corpo. Para os autores: "nesse período, o foco do atendimento em saúde volta-se para a criança, chegando inclusive à indicação da suplementação alimentar, quando não da substituição definitiva do leite materno, sem considerar a posição da mulher no seu direito de decidir as questões relativas ao aleitamento materno".

Em estudo para avaliar conhecimento materno obtido no pré-natal, Sandre-Pereira et al. ${ }^{11}$ notou que a informação transmitida, quando estava relacionada à saúde da mulher, estava direcionada a dar condições ao aleitamento materno, priorizando o tratamento das mamas, o preparo do mamilo e a posição de amamentar, não havendo demonstração de conhecimento sobre vantagens da amamentação para a saúde da mãe. Já Percegoni et al. ${ }^{14}$ observaram que o aconselhamento dirigido à saúde materna se restringia a alertá-las para que devessem se alimentar bem.

Vantagens decorrentes da amamentação para a própria saúde podem enaltecer a motivação de mulheres em direção à prática. Mas, no presente estudo, o incentivo à amamentação predominou sob a ótica dos benefícios à criança de forma considerável, enquanto que vantagens à saúde da mulher que amamenta foram muito pouco citadas, chegando até mesmo a ocorrer depoimento contrário à saúde materna, conforme relato: "Vou amamentar porque faz bem para o bebê, não para mim, mas para ele".

A praticidade tem sido apontada como vantagem para a mulher que amamenta ${ }^{3}$, considerando o indispensável rigor higiênico-sanitário que deve envolver a alimentação pela mamadeira. A praticidade conferida pela amamentação foi muito pouco encontrada nos motivos das gestantes deste estudo, pois somente duas delas $(1,2 \%)$ alegaram: "... é mais fácil do que ficar dando mamadeira daqui ... dali ..." e "... porque faz bem e acho cômodo!".

No estudo de Silva ${ }^{10}$ a praticidade aparece como vantagem por eliminar o trabalho de fazer ou aquecer mamadeira de madrugada, favorecendo a opção pelo aleitamento materno, pelo menos, em mamadas noturnas. Ter de transportar mamadeira e alimentos ao sair de casa com o filho também favorecia a preferência da mãe pela alimentação ao peito.

A responsabilidade do bebê pela amamentação foi identificada em um dos motivos alegados que parecia depender do ato reflexo da criança em procurar a mama e estava, portanto, relacionada à sucção do bebê. Neste caso, o motivo para amamentar dependia da atuação da criança em procurar pela mama e consistiu na seguinte resposta: "... eles procuram (o peito) sempre dei ...". 
Para Silva ${ }^{10}$ este comportamento da criança, no que diz respeito à sua habilidade em apreender o mamilo e desenvolver a sucção, é interpretado pela mãe como indicador da aceitação do leite materno e, em sentido mais amplo, da aceitação do peito, enquanto que a dificuldade em apreender o mamilo, por parte do recémnascido, é vista pela mãe como não aceitando o peito $^{10}$. A expressão orofacial da criança devido ao reflexo de procura também pode ser interpretada pela mãe como resposta de desprazer ou desagrado do lactente aos sabores do leite do peito ${ }^{17}$.

O comportamento infantil no período de amamentação deve ser abordado durante as orientações dirigidas às mulheres, para evitar que elas conjeturem sobre sua capacidade de amamentar e de seu leite ser suficiente para sustentar a criança, inibindo a adoção de substitutos que produzem mais saciedade, e a convicção rumo ao desmame.

Dificuldade com as mamas pela presença de mamilos invertidos surgiu no relato de uma das mulheres $(0,6 \%)$ como motivo desfavorável ao aleitamento materno, que exclamou: "Quero! Mas não consigo, porque tenho o bico do peito invertido!" Reis ${ }^{18}$, ao estudar o imaginário de mulheres com alterações anatômicas da mama, concluiu não ser possível compreender tal fenômeno sem levar em consideração o significado de mamas para a condição de gênero feminino.

A presença de mamilo invertido pode impor-se como barreira à amamentação, caso não haja manejo por parte da assistência, à dupla mãe e filho. Pode consistir em impedimento físico com repercussão negativa no imaginário materno, significando a amputação para o ato de amamentar, por descaracterizar a mulher anatomicamente da sua condição de mãe suficientemente $\mathrm{boa}^{4}$ conforme crença e legitimada pela literatura médica clássica de Winicott.

Quando amamentar é opção da mãe, mamilos invertidos tendem a se normalizar com exercícios específicos desde a gestação ou com a sucção insistente do bebê em pega correta ${ }^{7}$. No entanto, a gestante que referiu: "Quero! Mas não consigo, porque tenho o bico do peito invertido!", não havia recebido nenhuma orientação sobre preparo das mamas ou de posicionamento da criança em relação ao corpo da mãe.

A experiência bem sucedida em relação ao aleitamento materno do filho anterior predispõe a mulher a amamentar um novo bebê durante mais tempo ${ }^{7}$ e de forma exclusiva ${ }^{5,6}$. Neste estudo, a experiência prévia se apresentou como um dos motivos favoráveis para amamentar o próximo filho. $\mathrm{O}$ argumento pôde ser identificado no relato de uma das mulheres que esclareceu "... amamentei meu filho antes e ele é forte! ...". Dessa forma, a experiência bem sucedida em relação ao aleitamento materno pode ser um precedente positivo na intenção de amamentar o próximo filho, com o que se reforça a importância de um manejo adequado do processo de introdução da alimentação complementar, principalmente, para mulheres nulíparas. Em estudo conduzido na cidade de São Paulo foi observado que mulheres com pelo menos um filho anterior têm, em geral, mais conhecimento sobre variedade de alimentos da dieta infantil quando comparadas às mulheres sem filhos ${ }^{5,6}$.

Os sensos de obrigatoriedade e de dever encontrados nas frases de $2,4 \%$ de mulheres que alegaram "porque tem que amamentar a criança quando nasce!", possibilitou a identificação dos processos de responsabilização e culpabilização, amplamente enfatizados por Almeida ${ }^{3}$. Nakano \& Mamede ${ }^{13}$, também discutem esses fenômenos sociais apontados em direção à mulher no cuidado da criança. Nesta população, a responsabilização tende a ocorrer para justificar o motivo de, inclusive, ser amamentado, conforme acrescentou uma das entrevistadas: "eles (referindo-se aos bebês anteriores) sempre procuram ... (o peito) eu sempre dei!".

Na prática, os resultados decorrentes da amamentação, tanto de sucesso como de fracasso, serão sempre atribuídos como de responsabilidade da mulher ${ }^{3}$, desencadeando o processo de culpa ${ }^{19}$ e demais ressentimentos que se incutem 
na saúde emocional da mulher, podendo interferir na construção da relação mãe e filho.

A obrigação de amamentar foi evidenciada no relato: "... vou dar o peito porque tem que amamentar a criança quando nasce!". Esta fala reflete o modo como a sociedade, na qual se inclui o profissional de saúde, determina o aleitamento materno para a mulher, sem se dedicar a ouvi-la sobre sua decisão. O incentivo se dá desrespeitando o direito da mulher no seu processo de decisão pela prática20. Ao se apoiar nos conceitos de que a amamentação é um fenômeno natural e um direito da criança, o profissional prioritariamente defende a criança, deixando de considerar a perspectiva da mulher no curso do aleitamento materno ${ }^{20}$.

Por conseguinte, é possível observar na fala materna: "... porque tem que amamentar a criança quando nasce ..., "que o condicionamento exer-cido sobre a mãe sugere o senso de dever de, pelo menos, iniciar o aleitamento materno, pois a frase "quando nasce ..." revela que a intenção de amamentar tenderá a se limitar à proximidade do nascimento ou parto.

Para Silva ${ }^{20}$, a crença por parte da equipe de saúde sobre os deveres maternos para com a amamentação é adquirida desde o ambiente familiar e reforçada pelo aprendizado de conteúdos biológicos do aleitamento materno para a saúde da criança. A incorporação desses elementos colabora para que o profissional de saúde fique convencido que amamentar é um ato natural e próprio da mulher, sendo dever dela amamentar o filho.

Para Nakano \& Mamede $^{13}$, existe na sociedade uma exaltação de sentimentos prazerosos e do sofrimento, como parte do processo normal do aleitamento materno. Durante este período, a mulher é levada a provar suas virtuosidades à condição de mãe e de provedora fazendo justiça ao preceito popular "ser mãe é padecer no paraíso". De acordo com Morris ${ }^{21}$, a experiência de dor inerente a esta fase é decorrente do cristianismo e tende a ser interpretada como punição de Deus à sedução da mulher, redimindo-a simbolicamente da condição de pecadora. Para Adorno ${ }^{22}$, essa representação pode ser atribuída ao processo de alteridade do conteúdo teológico, pois, segundo ele: "nada do conteúdo teológico manter-se-á inalterado; tudo terá que se submeter à prova da emigração para o secular, o profano". Assim, a vertente religiosa influenciou o saber popular no trato com mulheres, contribuindo para a construção de significados religiosos que se coadunam com a crença de que sentindo dor, a mãe irá realizar-se completamente como mulher ${ }^{21}$.

O prazer e a beleza foram encontrados nos relatos de $4 \%$ de gestantes que respondiam: "... porque acho gostoso!" e ou "porque acho bonito!" Dessa forma, as mulheres que pretendem amamentar tendo como motivo o senso de beleza: "porque acho bonito" e a sensação de prazer: "porque acho gostoso", expressam certa autonomia e liberdade ao se verem confortáveis na experiência de nutriz perante si mesmas, seus respectivos filhos e perante os outros. Elas contrariam a motivação centrada no fardo de responsabilidade e culpa ou vinculada ao sofrimento virtuoso e sagrado.

Ao longo da história a mulher sempre desenvolveu atividades para além da maternidade, propiciando que o trabalho materno remunerado se tornasse uma condição cada vez mais comum. Segundo dados da Fundação Seade $^{23}$, a taxa de participação feminina no mercado de trabalho na metrópole de São Paulo representa mais de $53 \%$ das mulheres economicamente ativas e vem crescendo continuamente nos últimos anos. A proporção de mulheres trabaIhando cresce em todos os níveis de escolaridade, mas o crescimento tem sido mais intenso entre aquelas que apresentam entre 9 a 11 anos de estudo ${ }^{24}$, coincidindo com o grau de escolaridade mais freqüente da população de gestantes do presente estudo.

A escolaridade materna favorece a aquisição de conhecimento durante o pré-natal, ampliando a duração do aleitamento materno ${ }^{5,8}$. Por outro lado, a escolaridade facilita a inserção da mulher no mercado de trabalho e com isso impõe 
limitações à amamentação de forma exclusiva. Contudo, a escolaridade não resultou em melhor conhecimento sobre alimentação infantil e, tampouco foi obtida associação estatisticamente significante entre escolaridade e intenção para amamentar mais tempo e ou de forma exclusiva ${ }^{5,6}$.

O trabalho materno foi o principal motivo de preocupação apresentado para não pretender amamentar (Tabela 1). Este motivo, em síntese, pôde ser observado com a gestante que justificou: "... não vou amamentar porque não quero que ele (o bebê) sofra quando eu vou voltar ao trabalho, preciso trabalhar! ..." Também era comum entre as gestantes que relataram a ocupação com o trabalho fora do lar, a intenção de oferecer outro leite pela mamadeira, com o objetivo de evitar o sofrimento da criança com o desmame brusco no iminente retorno ao trabalho.

A política de aleitamento materno somente pela ótica da criança tem sido insuficiente para garantir comprometimento da mulher para com esta prática ${ }^{14}$. A busca de resultados rápidos como indicadores de qualidade de vida nos paises em desenvolvimento, tem conduzido o serviço de saúde a transgredir o direito da mulher de se decidir sobre algo que ocorre no próprio corpo ${ }^{25}$. Godoy \& Bouttelet ${ }^{19}$ acrescentam que: "nessas ocasiões deixamos de ouvir a pessoa como um todo, correndo o risco de criar mais um problema, estimulando o sentimento de culpa, além de não garantirmos com a nossa fala que ela vá amamentar o seu filho e ainda dificultamos que ela possa assumir com tranqüilidade a posição de não querer amamentar, um direito que é seu".

Em relação à atuação da assistência à saúde materna, Silva ${ }^{20}$ declara que os profissionais de saúde: "esquecem de que o núcleo do processo de amamentar é a mulher. É a mulher que vê a amamentação pelos olhos de mãe, julgando benefícios e riscos para o filho, mas também a mulher que enxerga na amamentação: riscos e benefícios para si. É a mulher que desempenha papéis transitórios, como o de gestante, e definitivos como o de mãe e, acima de tudo, o papel de 'mulher' quer para si ou para a sociedade".
A amamentação é condicionada aos aspectos socioculturais e sua prática precisa ser aprendida e protegida pela sociedade ${ }^{3}$. Ainda segundo Almeida3: "A dinâmica destas relações, no que concerne às questões estruturais, termina por configurar a amamentação como um dos atributos que caracterizam a maternidade como um bem social compartilhado". Esta partilha do cuidar, a depender do tipo de interação pode, segundo Silva ${ }^{20}$, se transformar em limites e facilidades nas tomadas de decisão quanto ao amamentar $^{20}$.

Pelo que foi percebido no campo da assistência pré-natal, durante o processo de incentivo à amamentação, o leite materno é exaustivamente valorizado, o que sobrepõe à presença materna, dando a impressão de que o que importa é o seu leite, o produto do seu corpo, como se este fosse dotado de inteligência, enquanto a mulher é vista, pela equipe de saúde, como condição favorável, a depender de sua motivação que se resume em afirmar o interesse em amamentar, um dos seus deveres de mãe, sem oportunidade de interagir como sujeito de argumentos.

Gadamer ${ }^{26}$, em O Mistério da Saúde, propõe uma reflexão aos profissionais de saúde sobre a objetivação da ciência e questiona o alcance da intervenção da nossa própria ação em meio ao aparelho automatizado, burocratizado e tecnificado em funcionamento nas diferentes dimensões da vida social. Sobre o propósito de se colocar a serviço do outro, que se aplica ao processo de assistência, ele se refere a um movimento de doação e dualidade "que se ultrapassa e se transforma no nada do ser-outro, que se extingue".

Resta a dúvida sobre o quanto a objetivação da política de amamentação, sob uma ótica fundamentada na fisiologia da lactação e na bioquímica do leite humano em supremacia ao ser pensante, não estaria com estes modos de intervenção em acordo ao existir de maneira passiva, permissiva e que se dispõe ao sacrifício. Ainda mais se levado em conta que, para 
Gadamer $^{26}$ ter saúde não é apenas sentir-se saudável, mas é um "estar-aí, estar-no-mundo, é um estar-com-os-outros, um sentir-se satisfeito com os afazeres da vida e manter-se ativo neles".

No período gestacional quando se coloca a questão do aleitamento materno, a mulher é impedida de interagir racionalmente com o outro. A mulher se cala perante o discurso da assistência mesmo consciente de suas reais possibilidades e intenções, não se vê no direito de contrariar o saber técnico-científico, nem mesmo na condição de outro, torna-se ela mesma condição. O profissional de saúde é o sujeito da ação, a criança: o outro e a mulher-mãe: condição favorável ou não, a depender da motivação em consentir a prescrição idealizada por seis meses.

No espaço da assistência pré-natal, a mãe se depara com a limitação de não ser vista como mulher, de não ser vista integralmente como sujeito, nem considerada a demanda de responsabilidade que envolve o seu cotidiano e, na condição de não-dona do saber, como simples figurante do popular, sem tom na voz para indagar o que de fato tem a ver com sua realidade, ela consente o processo de saber fora dela e de seu contexto, sem acolhimento nem demora, o mundo branco continua vazio. Assim, mediante a atitude que a vê desprovida de noção do que, de fato, ocorre ao seu redor, tomando como próprias palavras de Ramos \& Almeida27, ela "se recolhe à condição de paciente e como tal, passa a compreender aqueles que deveriam compreendê-la".

Na concepção de Gadamer ${ }^{26}$ a respeito do que é um tratamento, "tratar consiste antes em falar ao outro de bom modo, em não o forçar, não o incomodar com algo, não o obrigar a aceitar algo, por exemplo, uma medida ou prescrição". Dessa forma, quando se adota a responsabilidade sobre aquele que é assistido implica deixar lugar à liberdade de decisão. A liberdade de poder continuar aos cuidados mesmo manifestando decisão contrária. O conflito de saberes científicopopular tende a repelir a mulher e a criança para longe da assistência. Para Gadamer ${ }^{26}$, um tratamento, ensino e aprendizado, não é "simples coincidência de causa e efeito, de intervenção e êxito, mas de uma harmonia oculta, cuja recuperação é o que importa e na qual radicam, em definitivo, o milagre da convalescença e o mistério da saúde".

A rigor, o diálogo, tentativa de entendimento, faz parte da assistência porque humaniza a relação, significando as diferenças entre o profissional da saúde e o paciente. Nesse sentido, "o estabelecimento das relações desiguais é uma das tarefas mais difíceis entre os homens" ${ }^{26}$. Não obstante, para Habermas ${ }^{28}$ em sua Dialética da Razão, as pessoas falam com as outras porque são obrigadas a agir comunicativamente, como sujeitos capazes de consenso, porque as idealizações pelo entendimento na prática cotidiana pertencem à linguagem coloquial. Em contrapartida, a compreensão, segundo Gadamer ${ }^{26}$, é um aspecto integral da existência humana. Uma vez compreendida, a mensagem, ela atua como uma ponte entre o intérprete e o discurso, gerando um processo de interação crítica.

Em vista disso, a assistência pré-natal consiste em uma excelente oportunidade para agregar motivação às mulheres por meio de linguagem acessível, com exemplos práticos e viáveis. A questão que se coloca é a da comunicabilidade na qual se caracteriza o educar. A transposição da ação educativa para o espaço do cuidar ou do tratar vê-se diante das palavras de Ayres 29 : "educar é perceber e trabalhar com a efetiva presença de um sujeito diante de outro sujeito". É nessa mútua presença que ocorre o encontro do terceiro elemento que ele chama de "objeto de aprendizado". No caso da motivação para amamentar, o processo perpassa a vontade feminina e sua construção parece se dar muito mais no espaço do educar do que no do tratar.

Dessa forma, no processo de incentivo para o aleitamento materno a mulher encontrase diante de um conflito que pode ser amenizado, ou transformado em uma circunstância optativa, na trajetória da decisão. Por um lado: o direito dela em ter autonomia sobre seu querer e corpo, por outro lado: encontram-se os direitos da criança 
à alimentação adequada ${ }^{25}$. Contudo, para consolidar o direito subjetivo da mulher emancipada, segundo Habermas ${ }^{30}$, aquela que age comunicativamente visando conseguir acordos consensuais, faz-se necessário validar essa prática, ao menos, na relação com profissionais de saúde. Afinal, emancipação tem o seu lugar no âmbito do intercâmbio do sujeito consigo mesmo.

Do ponto de vista da assistência, a motivação para o aleitamento materno deveria suceder a descoberta ou a expressão da vontade da mulher sobre o assunto. Intermediar o processo de tomada de decisão, sem julgamento e imposição, com o senso de promover conquista de autonomia na mulher. Acolher a decisão da mãe pelo melhor para si e para quem dela provém. Incentivar a amamentação requer sua reconstrução enquanto prática social. Neste interim, nada mais pertinente que a afirmação de Habermas ${ }^{28}$ : "nós descobrimos quem somos porque aprendemos, ao mesmo tempo, a nos ver numa relação com os outros".

\section{O N CLUS Ã O}

Identificar o desejo materno em amamentar pode indicar à assistência a natureza do debate que envolve o processo de decisão da mulher pela amamentação. Práticas assistenciais baseadas no diálogo e no respeito à opinião da mulher, em acordo ao contexto e ao saber popular, podem contribuir no esclarecimento do que de fato motiva a decisão e manutenção do aleitamento pela mulher no papel de mãe.

\section{COLABORADORES}

S.A.M. TAKUSHI, autora do projeto de pesquisa. Responsável pela elaboração do instrumento de coleta, pela coleta e pela criação do banco de dados em categorias; análise e primeira escrita do manuscrito e articulação das várias opiniões/perspectivas dos autores no manuscrito. A.C. d'A. TANAKA, co-autora do projeto de pesquisa, responsável pela articulação com os serviços nos quais foi realizada a pesquisa. Sugeriu referências que embasaram o projeto e participou da elaboração das categorias para análise e escrita. P.R. GALLO participou do desenho do projeto e sugeriu todas as referências que abrangessem a perspectiva infantil. Também colaborou na discussão e revisão dos conceitos do manuscrito. M.A.M.P. MACHADO foi a principal interlocutora em todos os momentos de andamento do projeto. Contribuiu com a sugestão de referências e permitiu o diálogo da parte mais psicanalítico-filosófica do material. Também colaborou com a síntese do manuscrito.

\section{REFERÊ NCIAS}

1. Del Priore M. História das crianças no Brasil. São Paulo: Contexto; 1999.

2. Novaes HMD. A puericultura em questão [dissertação]. São Paulo: Universidade de São Paulo; 1979.

3. Almeida JAG. Amamentação: um híbrido naturezacultura. J Pediatr. 2004; 80(5):119-25.

4. Winnicot DW. A criança e seu mundo. Rio de Janeiro: Zahar; 1966.

5. Takushi SAM. Alimentação complementar na opinião de gestantes [dissertação]. São Paulo: Universidade de São Paulo; 2003.

6. Takushi SAM, Tanaka ACA, Gallo PR, Bresolin AMB. Perspectiva de alimentação infantil obtida com gestantes atendidas em centros de saúde na cidade de São Paulo. Rev Bras Saude Mater Infant. 2006; 6(1):115-25.

7. Sanches MTC. Manejo clínico das disfunções orais na amamentação. J Pediatr. 2004; 80(5):155-62.

8. Giugliani ERJ, Rocha VL, Neves JM, Polanczyk CA, Seffrin CF, Susin LO. Conhecimentos maternos em amamentação e fatores associados. J Pediatr. 1995; 71(2):77-81.

9. Marques NM, Lira PIC, Lima MC, Silva NL, Batista Filho M, Huttly SRA, et al. Breastfeeding and early weaning practices in Northeast Brasil: a longitudinal study. Pediatrics [e-journal]. 2001. [cited 2003 May 20]; 108 (4):e66. Available from: <http://mww.pediatrics.org/cgi/content/full/108/4/e66>.

10. Silva IA. Amamentar: uma questão de assumir riscos ou garantir benefícios [tese]. São Paulo: Universidade de São Paulo; 1994.

11. Sandre-Pereira G, Colares LGT, Carmo MGT, Soares EA. Conhecimentos maternos sobre amamentação entre puérperas inscritas em programa de prénatal. Cad Saúde Pública. 2000; 16(2):457-66. 
502 S.A.M. TAKUSHI et al.

12. Bauer MW, Gaskel G. Pesquisa qualitativa com texto, imagem e som. Um manual prático. Rio de Janeiro: Vozes; 2004.

13. Nakano AMS, Mamede MV. A prática do aleitamento materno em um grupo de mulheres brasileiras: movimento de acomodação e resistência. Rev Latino-Am Enfermagem. 1999; 7(3):69-76.

14. Percegoni N, Araújo RMA, Silva MMS, Euclydes MP, Tinoco ALA. Conhecimento sobre aleitamento materno de puérperas atendidas em dois Hospitais de Viçosa, Minas Gerais. Rev Nutr. 2002; 15(1): 29-35.

15. Stabe C. Retenção de peso pós-gestacional e aleitamento materno [dissertação]. São Paulo: Universidade de São Paulo; 2002.

16. Moreira KFA, Nakano AMS. Aleitamento materno: Intuitivo? Natural: o paradigma biológico $X$ os direitos reprodutivos em discussão. Rev Bras Enferm. 2002; 55(6):685-90.

17. Blass EM. Suckling: determinants, changes, mechanisms, and lasting impressions. Dev Psychol. 1990; 26(4):520-33.

18. Reis AOA. Repercussões psicossociais. In: Boff RA, Kavanagh JJ. Ginecologia e mastologia: um guia prático. Caxias do Sul: Universidade de Caxias do Sul; 2002. p.803-31.

19. Godoy MTH, Bouttelet D. Repensando o cuidado à mulher que amamenta. Rev Bras Cresc Desenv Hum. 2004; 14(1):68-74.

20. Silva IA. Construindo perspectivas sobre a assistência em amamentação: um processo interacional [tese]. São Paulo: Universidade de São Paulo; 1999.
21. Morris DB. The culture of pain. Berkeley, CA: University of California Press; 1993.

22. Adorno TW. Teoria estética. Lisboa: Edições 70; 1992.

23. Fundação Seade. Mercado de Trabalho. Convênio Seade - Dieese. Pesq Emprego Desemprego - PED. 2001 [acesso 2003 maio 20]; (1). Disponível em: $<$ http://www.seade.gov.br/>

24. Itaboraí NR. Trabalho feminino e mudanças na família no Brasil (1984-1996): explorando relações. Rev Bras Estud Popul. 2003; 20(2):157-76.

25. França Junior I, Ayres JRCM. Amamentar é um direito humano? São Paulo: SENAC; 2000.

26. Gadamer HG. O mistério da saúde: o cuidado da saúde e a arte da medicina. Lisboa: Edições 70; 1993.

27. Ramos CV, Almeida JAG. Aleitamento materno: como é vivenciado por mulheres assistidas em uma unidade de saúde de referência na atenção materno-infantil em Teresina, Piauí. Rev Bras Saúde Mater Infant. 2003; 3(3):315-21.

28. Habermas J. Passado como futuro. Rio de Janeiro: Tempo Brasileiro; 1993.

29. Ayres JRCM. Práticas educativas e prevenção de HIV/AIDS: lições aprendidas e desafios atuais. Interface - Comun Saúde, Educ. 2002; 6(11):11-24.

30. Habermas J. Direito e democracia: entre a facticidade e validade. Rio de Janeiro: Tempo Brasileiro; 1997.

Recebido em: 13/11/2006

Versão final reapresentada em: 29/6/2007

Aprovado em: 18/6/2008 